\title{
Conventional and molecular epidemiology of Tuberculosis in Manitoba
}

\author{
Kym S Blackwood*1, Assaad Al-Azem², Lawrence J Elliott ${ }^{2}$, Earl S Hershfield ${ }^{3}$ \\ and Amin M Kabani1,3,4
}

Address: ${ }^{1}$ National Reference Center for Mycobacteriology, National Microbiology Laboratory, Health, Canada, Winnipeg, MB, Canada, 2Department of Community Health Sciences, University of Manitoba, Winnipeg, MB, Canada, ${ }^{3}$ Department of Medicine, University of Manitoba, Winnipeg, MB, Canada and ${ }^{4}$ Department of Clinical Microbiology, Health Sciences Center, Winnipeg, MB, Canada

Email: Kym S Blackwood* - kym_blackwood@hc-sc.gc.ca; Assaad Al-Azem - umalmoua@cc.umanitoba.ca;

Lawrence J Elliott - elliottl@cc.UManitoba.CA; Earl S Hershfield - ehersh@ccu.umanitoba.ca; Amin M Kabani - amin_kabani@hc-sc.gc.ca

* Corresponding author

Published: 13 August 2003

BMC Infectious Diseases 2003, 3:18
Received: II June 2003

Accepted: 13 August 2003

This article is available from: http://www.biomedcentral.com/I47I-2334/3/18

(c) 2003 Blackwood et al; licensee BioMed Central Ltd. This is an Open Access article: verbatim copying and redistribution of this article are permitted in all media for any purpose, provided this notice is preserved along with the article's original URL.

\begin{abstract}
Background: To describe the demographic and geographic distribution of tuberculosis (TB) in Manitoba, thus determining risk factors associated with clustering and higher incidence rates in distinct subpopulations.

Methods: Data from the Manitoba TB Registry was compiled to generate a database on 855 patients with tuberculosis and their contacts from 1992-1999. Recovered isolates of M. tuberculosis were typed by IS6 I I 0 restriction fragment length polymorphisms. Bivariate and multivariate logistic regression models were used to identify risk factors involved in clustering.

Results: A trend to clustering was observed among the Canadian-born treaty Aboriginal subgroup in contrast to the foreign-born. The dominant type, designated fingerprint type I, accounts for $25.8 \%$ of total cases and $75.3 \%$ of treaty Aboriginal cases. Among type I patients residing in urban areas, $98.9 \%$ lived in Winnipeg. In rural areas, $92.8 \%$ lived on Aboriginal reserves. Statistical models revealed that significant risk factors for acquiring clustered tuberculosis are gender, age, ethnic origin and residence. Those at increased risk are: males $(p<0.05)$; those under age $65(p<0.01$ for each age subgroup); treaty Aboriginals $(p<0.00 \mathrm{I})$, and those living on reserve land $(p<0.00 \mathrm{I})$.

Conclusion: Molecular typing of isolates in conjunction with contact tracing data supports the notion of the largest ongoing transmission of a single strain of TB within the treaty-status population of Canada recorded to date. This data demonstrates the necessity of continued surveillance of countries with low prevalence of the disease in order to determine and target highrisk populations for concentrated prevention and control measures.
\end{abstract}

\section{Background}

Tuberculosis (TB) has infected one-third of the world population and kills three million people each year. Glo- bally, TB is considered the most common cause of death from a single infectious organism, Mycobacterium tuberculosis [1-3]. Canadians have a long history of suffering 
tremendously from TB. In the $19^{\text {th }}$ century, one fifth of Canadians were infected with this disease and large numbers died. In the beginning of the $20^{\text {th }}$ century, the mortality rate among Aboriginal people of Saskatchewan and Alberta reached as high as 9,000 per 100,000 [4,5].

Improvements in socioeconomic conditions, public health services, drug therapy and medical surveillance in Canada markedly reduced the mortality rate $[0.4$ per 100,000 by 1987] and overall incidence rates (5.9 per 100,000 by 1998) [6]. However, certain groups in Canada are at higher risk for acquiring $\mathrm{TB}$, such as the Aboriginal population (defined as status and non-status Indian, Metis, Inuit, and Innu), foreign-born individuals from countries with high prevalence rates of $\mathrm{TB}$, the homeless and the HIV-infected population [6]. In 1998, the incidence rate among non-Aboriginal Canadians was 1.5 per 100,000; in contrast, the status Indian, total Aboriginal and foreign-born population had incidence rates of 35.4, 22.5 and 21.4 per 100,000 respectively [7]. Furthermore, the proportion of TB cases reported in Canada from the foreign-born population has increased, from 35\% in 1980 to $64 \%$ in 1998 [7]. In an attempt to eliminate tuberculosis in Canada, the Tuberculosis Prevention and Control Unit of Health Canada implemented guidelines recommended by the World Health Organization in 1997 [6]. Despite adoption of these guidelines, incidence rates of $\mathrm{TB}$ are still high in certain geographic and demographic zones, making elimination of the disease by recommended time periods put forth by Health Canada an increasingly difficult goal $[6,8]$. Currently, incidence rates in Canada have leveled off and remain fairly constant due to these sustaining population subgroups.

The majority (75\%) of TB patients in Canada live in three provinces: Ontario, Quebec and British Columbia. Furthermore, $90 \%$ of all TB cases in the country attributed to the foreign-born population reside in these provinces [9]. In Manitoba however, the composition of TB patients is distinctly different: the majority of TB cases are among Canadian-born, with the highest incidence among treaty Aboriginals (48.4 per 100,000 overall, with rates as high as 496.3 per 100,000 in select communities $[10,11]$.

These distinct epidemiological patterns merited a further examination. Consequently, in this study, both conventional in conjunction with molecular methods were used to describe the epidemiology of tuberculosis in Manitoba from 1992 to 1999. The objectives of the study were to describe subgroups within Manitoba at high risk for developing $\mathrm{TB}$, and to define risk factors and possible reasons for the ongoing transmission in order to better target prevention and control programs.

\section{Methods \\ Setting}

Manitoba has a population of 1.14 million (Statistics Canada, 1996). 78.1\% are Canadian-born (CB) nontreaty, $8.9 \%$ are treaty Aboriginals, and the remainder is foreign-born (FB) $[12,13]$. It is unknown how many Aboriginal individuals have not claimed treaty status. All diagnosed cases of tuberculosis in Manitoba are registered in the Manitoba Central Tuberculosis Registry (MCTR) at the Health Sciences Center (HSC) in Winnipeg. Case finding in Manitoba is done by clinical diagnosis of symptomatic patients and by contact tracing. Administered treatment is drug therapy of a combination of first line antituberculosis drugs: rifampin, isoniazid, pyrazinamide, ethambutol, and/or streptomycin. Direct observed therapy (DOT) verifies a completed course of treatment. Ninety-five percent of patients under DOT complete treatment in Manitoba [8].

\section{Sample Data}

Data on all TB patients and identified contacts from January 1, 1992 to December 31, 1999 was obtained from the MCTR. Data fields such as the patient's unique identifier number, date of birth, birthplace, sex, country of birth, postal code, origin ( $\mathrm{CB}$ treaty / non-treaty or $\mathrm{FB}$ ), date of diagnosis, case finding method, TB status (new, active or relapse), BCG status, year of landing (foreign patients), smear results, culture results, TB DNA fingerprint type, drug resistance, chest X-rays and cavity status were extracted from the patient records and the information was entered into a database. This data set did not include patient name, allowing data analysis while maintaining the patient confidentiality. Specimens were collected by designated medical staff at the Respiratory Clinic, HSC, and other health care centers in Manitoba. The collected samples were sent to the Clinical Microbiology Laboratory at HSC for isolation and identification of M. tuberculosis. The Accuprobe M. tuberculosis complex kit (GenProbe Incorporated, San Diego, CA, USA) was used to identify M. tuberculosis in the clinical samples. Samples were subsequently processed for DNA sub-typing according to the internationally standardized methodology of IS6110 restriction fragment length polymorphisms (RFLP) [14]. Procedures outlined by Small et. al. to minimize the possibility of cross-contamination [15] was strictly adhered to by staff at the HSC and no evidence of cross-contamination was observed.

\section{RFLP Analysis}

All gel pictures containing the IS6110 RFLP patterns were analyzed to determine clustering using Molecular Analyst ${ }^{\oplus}$ Software Fingerprinting version 1.12, BioRad, Hercules, CA, USA. Clustering establishes groups of patients from which isolates with identical or near identical fingerprints are found and are likely to be linked epidemiologically 
Table I: Bivariate logistic regression analysis of risk factors associated with clustering.

\begin{tabular}{|c|c|c|c|c|c|}
\hline Characteristic & Incidence & Clustered & Non-Clustered & Odds Ratio & $p$ value \\
\hline & (person-year/l00 000) & $\mathrm{n}=426(\%)$ & $\mathrm{n}=203(\%)$ & $(95 \%) \mathrm{Cl}$ & \\
\hline \multicolumn{6}{|l|}{$\underline{\text { Sex }}$} \\
\hline Female & 8.4 & $167(39.2)$ & $102(50.2)$ & I (reference) & \\
\hline Male & 10.1 & $259(60.8)$ & $101(49.8)$ & $1.57(1.12-2.19)$ & 0.011 \\
\hline \multicolumn{6}{|l|}{ Age $*$} \\
\hline 0 to 14 & 3.1 & $18(4.2)$ & $4(2.0)$ & 4.61 (1.39-16.84) & 0.004 \\
\hline 15 to 24 & 5.8 & $51(12.0)$ & $17(8.4)$ & $3.07(1.58-6.03)$ & 0.000 \\
\hline 25 to 44 & 10.4 & $170(39.9)$ & $47(23.1)$ & $3.70(2.33-5.89)$ & 0.000 \\
\hline 45 to 64 & 10.7 & $102(23.9)$ & $48(23.6)$ & $2.17(1.35-3.52)$ & 0.000 \\
\hline $65+$ & 18.4 & $85(20.0)$ & 87 (42.9) & 1 & \\
\hline \multicolumn{6}{|l|}{ Origin } \\
\hline Canadian-Born (non-treaty) & 3.3 & $97(22.8)$ & $60(29.6)$ & 1 & \\
\hline Canadian-Born (treaty) & 48.4 & $254(59.6)$ & $27(13.3)$ & $5.82(3.46-9.54)$ & 0.000 \\
\hline Foreign-Born & 20 & $75(17.6)$ & $116(57.1)$ & $0.340(0.26 I-0.620)$ & 0.000 \\
\hline \multicolumn{6}{|l|}{ Residence } \\
\hline Winnipeg & 9.7 & $235(55.1)$ & $153(75.4)$ & 1 & \\
\hline other urban & 4.1 & $14(3.3)$ & II (5.4) & $0.829(0.369-1.829)$ & 0.809 \\
\hline reserves & 33.7 & $148(34.7)$ & $15(7.4)$ & $\begin{array}{c}6.424(3.563- \\
10.947)\end{array}$ & 0.000 \\
\hline other rural & 9.2 & $29(6.9)$ & $24(11.8)$ & $0.787(0.443-1.392)$ & 0.051 \\
\hline \multicolumn{6}{|l|}{ Site of Infection } \\
\hline Extrapulmonary & & III (26.I) & $66(32.5)$ & I & \\
\hline Pulmonary & & $315(73.9)$ & $137(67.5)$ & $1.367(0.95 \mathrm{I}-1.969)$ & 0.112 \\
\hline
\end{tabular}

$* \chi^{2}$ test for overall linear trend in age $=32.6, p<0.001$

[16]. Clustered cases were identified by searching each fingerprint against the created database containing all other patterns over the eight-year period using the Dice coefficient with $1.5 \%$ position tolerance and verified visually. Isolates with identical patterns or differing by a single band were considered the same [17]. All created databases were stored in Microsoft Access ${ }^{\circledast}$ and linked together utilizing the MCTR unique identifier numbers.

\section{Statistical Analysis}

Population figures from the 1996 Statistics Canada Census were used to calculate tuberculosis incidence rates. Since the study was conducted over an eight-year period, the person-year population of Manitoba throughout this time was determined by multiplying the 1996 population by eight. To determine the incidence rate for a specific population subgroup, we added all TB cases in that subgroup from 1992 to 1999 then divided by the total eightyear subgroup person-years. The resulting number was multiplied by 100,000 to obtain the incidence rate per 100,000 person-years. To compare risk factors for recent $\mathrm{TB}$ acquisition of the subpopulation of interest, we used clustering versus non-clustering (unique) as the outcome variable. Bivariate and multivariate logistic regression analyses were carried out using NCSS 2000 software (NCSS, Kaysville, UT, USA). Variables used in the bivari- ate model (table 1) were gender, age (five subgroups), ethnic origin (three subgroups), residence (four subgroups) and site of infection. A chi-squared test for linear trend was performed on the subgroups. Multivariate models using gender, age, ethnic origin, residence, site of infection, status (new or relapse), drug resistance, BCG status, chest $\mathrm{x}$-ray and cavity were analyzed and potential interactions were assessed for significance. Variables significant at the $\mathrm{p}<0.05$ level were kept in the final multivariate model, summarized in Table 2.

\section{Results}

\section{Tuberculosis Trends}

Between January 1st 1992 and December 31st 1999, there were 855 reported cases of tuberculosis in Manitoba. The majority of individuals with tuberculosis were born in Canada $(70.6 \%)$ and almost half of the total patients were CB with treaty status (44.4\%). Non-treaty CB individuals contributed $26.2 \%$ of total cases and FB population contributed $29.4 \%$ (figure 3 ).

The age distribution of $\mathrm{TB}$ cases varies between the three population subgroups. For the treaty status subgroup, the incidence in the oldest (65+) age group was 17.3 times that in the youngest $(0-14)$ age group, whereas this ratio 
Table 2: Multivariate logistic regression analysis of risk factors associated with clustering

\begin{tabular}{|c|c|c|c|c|c|}
\hline Characteristic & Incidence & Clustered & $\begin{array}{l}\text { Non-Clustered } \\
\text { (unique) }\end{array}$ & Odds Ratio & $P$ value \\
\hline & (person-year/l00 000) & $n=426(\%)$ & $n=203(\%)$ & $(95 \%) \mathrm{Cl}$ & \\
\hline \multicolumn{6}{|l|}{$\underline{\text { Sex }}$} \\
\hline Female & 8.4 & $167(39.2)$ & $102(50.2)$ & I (reference) & \\
\hline Male & 10.1 & $259(60.8)$ & I0I (49.8) & $1.959(1.306-2.938)$ & 0.0011 \\
\hline \multicolumn{6}{|l|}{ Age $*$} \\
\hline 0 to 14 & 3.1 & $18(4.2)$ & $4(2.0)$ & $2.55(0.74-8.88)$ & 0.1401 \\
\hline 15 to 24 & 5.8 & $51(12.0)$ & $17(8.4)$ & $2.53(1.20-5.34)$ & 0.0151 \\
\hline 25 to 44 & 10.4 & $170(39.9)$ & $47(23.1)$ & $3.26(1.92-5.54)$ & 0.0000 \\
\hline 45 to 64 & 10.7 & $102(23.9)$ & $48(23.6)$ & $1.47(0.87-2.50)$ & 0.1523 \\
\hline $65+$ & 18.4 & $85(20.0)$ & $87(42.9)$ & 1 & \\
\hline \multicolumn{6}{|l|}{ Origin $^{\dagger}$} \\
\hline Canadian-Born (non-treaty) & 3.3 & $97(22.8)$ & $60(29.6)$ & 1 & \\
\hline Canadian-Born (treaty) & 48.4 & $254(59.6)$ & $27(13.3)$ & $4.108(2.163-7.803)$ & 0.0000 \\
\hline Foreign-Born & 20.0 & $75(17.6)$ & $116(57.1)$ & $0.248(0.149-0.412)$ & 0.0000 \\
\hline \multicolumn{6}{|l|}{ Residence $^{\ddagger}$} \\
\hline Winnipeg & 9.7 & $235(55.1)$ & I53 (75.4) & 1 & \\
\hline other urban & 4.1 & $14(3.3)$ & II (5.4) & $0.490(0.195-1.230)$ & 0.1289 \\
\hline reserves & 33.7 & $148(34.7)$ & $15(7.4)$ & $1.206(0.546-2.665)$ & 0.6433 \\
\hline other rural & 9.2 & $29(6.9)$ & 24 (II.8) & $0.410(0.203-0.830)$ & 0.0132 \\
\hline
\end{tabular}

$*$ age overall effect, $\chi^{2}$ test $=21.83$ with 4 different factors, $p<0.001$ torigin overall effect, $\chi^{2}$ test $=81.54$ with 2 different factors, $p<0.001 \ddagger$ residence overall effect, $\chi^{2}$ test $=9.26$ with 3 different factors, $p<0.05$

was 10.9 for the non-treaty population, and only 1.3 for the foreign-born population (Figure 3 ).

Dividing Manitoba into rural and urban categories indicates that the majority of FB individuals and non-treaty Canadians with TB reside within the city of Winnipeg, while the majority of treaty-status individuals with $\mathrm{TB}$ reside in rural areas (figure 1). Winnipeg, as the major urban center of Manitoba, hosts $98.4 \%$ of all FB TB patients, and $62.8 \%$ of total patients. Aboriginal reserve land includes $22.1 \%$ (189) of total patients, with nine reserves in northern Manitoba harboring 159 (84\%) of these cases. The ТВ incidence rate per 100,000 personyears for these nine isolated communities ranged from 19.9 to 496.3 per community. Almost all of these cases were in registered treaty individuals. The remaining $15.1 \%$ of total patients live in urban areas other than Winnipeg and rural areas other than reserves. Individuals living in urban places other than Winnipeg or rural areas other than reserves experienced a rate of only 4.1 per 100,000 person-year. The overall Winnipeg incidence rate (9.7 per 100,000 person-years) was comparable to the overall Manitoba's rate (9.2 per 100,000 person-years).

\section{Molecular typing and clustering of cases}

Isolates of $M$. tuberculosis were obtained from a total of 629 patients $(73.6 \%)$ for molecular typing to establish clustering. The remaining balance of cases were diagnosed by means other than microbiological and thus no culture was available for sub-typing. The patient characteristics of these unavailable isolates were compared to those available to observe any significant differences that may affect estimation of clustering. The distribution of patients was roughly the same for both and was deemed not significant. Fingerprint patterns of less than six RFLP bands were observed in 15 isolates. These fingerprints did not cluster, and therefore secondary sub-typing of these isolates, i.e. spoligotyping, was not performed [16].

In total, 249 different fingerprints were obtained, and 203 of them were unique. The 46 that were not unique formed clusters that linked patients into groups containing as little as two and as many as 162 individuals per cluster. The dominant fingerprint type over the study period was fingerprint type 1 (FP1), a strain containing a 12-band IS6110 pattern that was tested sensitive to primary drugs. This strain afflicted $162(25.8 \%)$ individuals of the total TB population, with a very high proportion of treaty individuals $(75.3 \%)$ residing in both Winnipeg and reserves being infected. By contrast, the second most frequent fingerprint is type 2 , infecting only $32(5.1 \%)$ of the total population with TB. The top five fingerprint patterns in terms of prevalence are distributed as seen in figure 5 .

The distribution of clustering by the distinct sub-populations is also graphically represented in figure 4 . The treaty 


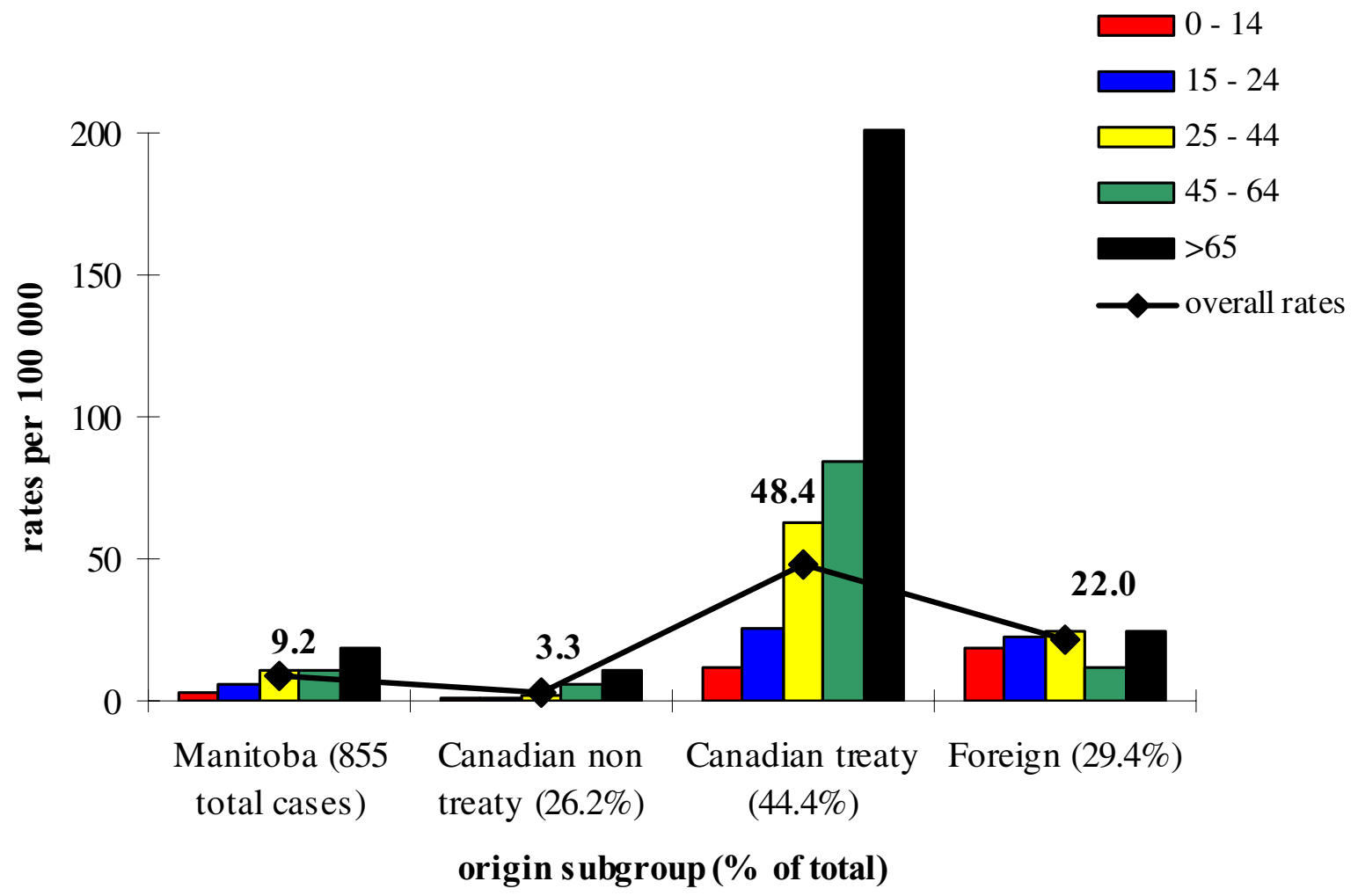

Figure 3

Tuberculosis incidence rates by age group and origin, 1992-1999.

subpopulation contributed 254 (59.6\%) of clustered cases; in contrast, the FB population comprised the majority of unique cases (57.2\%). Comparison of clustering among geographical subgroups also showed the highest proportion of clustering among the reserves and Winnipeg. Of the 162 FP1 cases, 93 (57.4\%) lived in urban areas, and of these, $98.9 \%$ were in Winnipeg. Of the 69 $(42.6 \%)$ living in rural areas, $92.8 \%$ resided on reserve land. Furthermore, Winnipeg presented the majority of unique fingerprint types, due to the large proportion of foreign-born persons residing in the city.

\section{Risk Factor Analysis}

Analysis of risk factors for clustering using both bivariate and multivariate analysis is summarized in tables 1 and 2 . Significant independent risk factors for clustering included gender, age, geographic residence and ethnic origin. Males are twice as likely to develop clustered TB than females (table 2). Treaty status patients are at four times higher risk of developing clustered TB than those without treaty status (reference subgroup), while in comparison, foreign-born patients are at one-quarter the risk for developing clustered TB compared to the reference population. TB patients in the four age groups under age 65 had risks of developing clustered TB that ranged from 1.5 to 3.3 times that of those over the age of 65 (table 2). Residence on a reserve was significant in the bivariate analysis: these patients have a five times higher risk of having clustered $\mathrm{TB}$ than the patient group that lives in Winnipeg. In the multivariate model, however, controlling for the other variables revealed that residence is not a significant independent risk factor, although living in a rural non-reserve area is protective (table 2 ). Finally, there was no evidence that patients with pulmonary TB had a higher risk of developing clustered TB than those with extra pulmonary TB. 


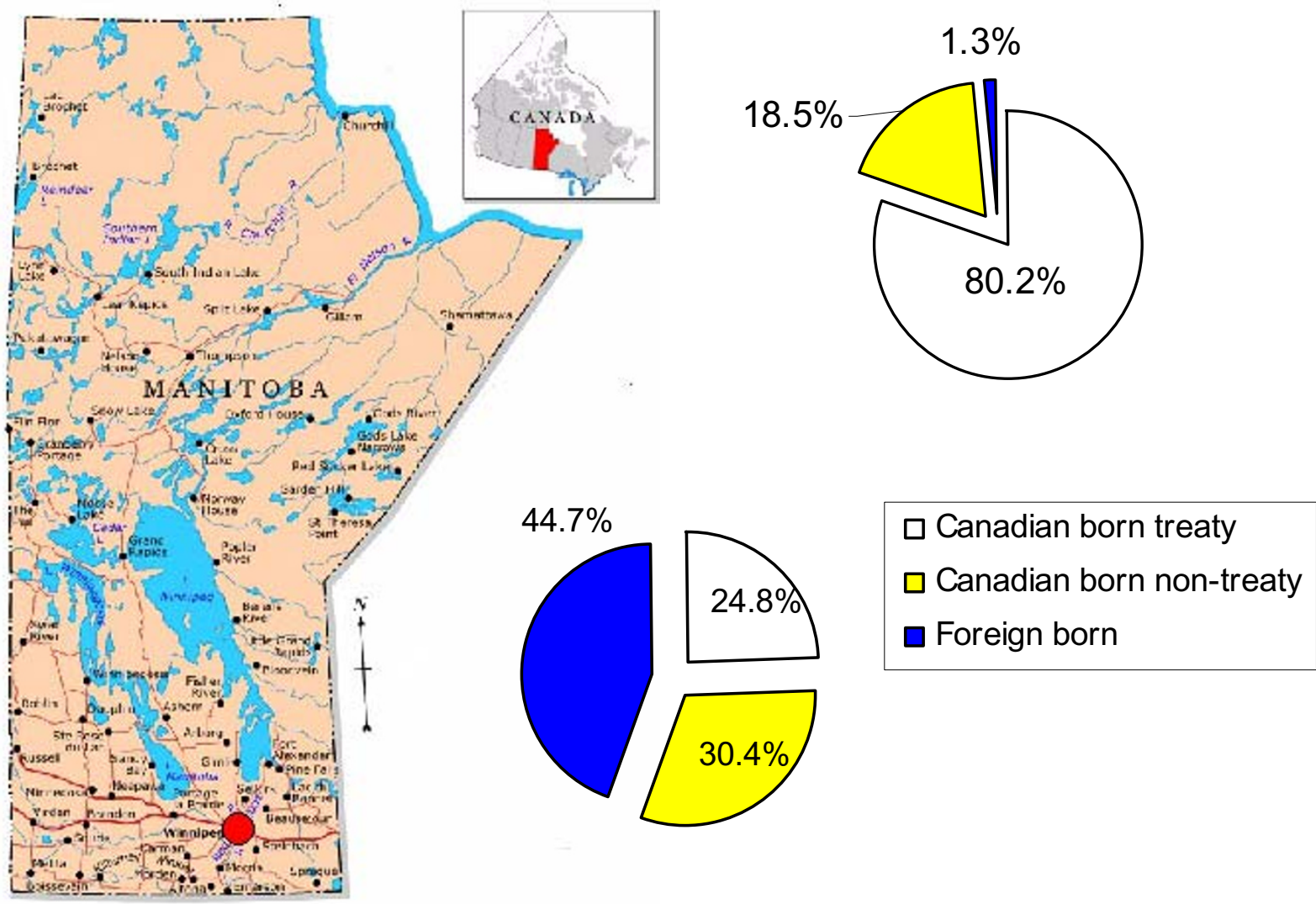

Figure I

Geographic distribution of tuberculosis patients in Manitoba, 1992-1999. Top chart represents rural Manitoba, in contrast, the bottom depicts urban Manitoba.

\section{Contact Tracing}

The largest cluster contained 162 cases that displayed FP1. Contact investigations were indicated on 121 of these cases, determining a total of 2195 contacts. 145 of those contacts presented with disease. Of the 145 contacts, 92 $(63.5 \%)$ harbored the FP1 strain of TB. $4(2.8 \%)$ had a fingerprint type other than FP1, and the remainder of cases did not have isolates available for typing purposes. Most exposures were from family members $(57.5 \%)$ or friends $(24.5 \%)$ in the home $(71.7 \%)$. Preliminary social network analysis using software packages Ucinet and Pajek revealed the spread of TB from Winnipeg to reserve land and vice versa.

\section{Discussion}

The end of World War II marked the beginning of a sharp decline in TB incidence rates in Canada. Unfortunately, the last 10 years have shown a leveling off of total incidence rates at approximately 7 per 100,000, with no appreciable decline (figure 2) $[6,7,9]$. Manitoba shares the same national trends $[7,10]$. Although rates have declined in every subpopulation, comparative rates among $\mathrm{CB}$ treaty individuals in Manitoba (48.4 per 100,000) are still more than ten times than those of the non-treaty subgroup (3.3 per 100,000), and more than two times those of the FB subgroup (22.0 per 100,000) (figure 3) $[10,11,18]$. Furthermore, whereas the overall majority of TB cases in Canada are attributed to immigration, the population distribution of tuberculosis in Manitoba is distinctly different than in the other provinces. While foreign-born cases represent $81 \%$ of Ontario TB patients, $48 \%$ of Quebec TB patients and $60 \%$ of TB patients in British Columbia, in contrast, they represent only $29 \%$ of the total ТВ cases in Manitoba between 1992 and 1999 

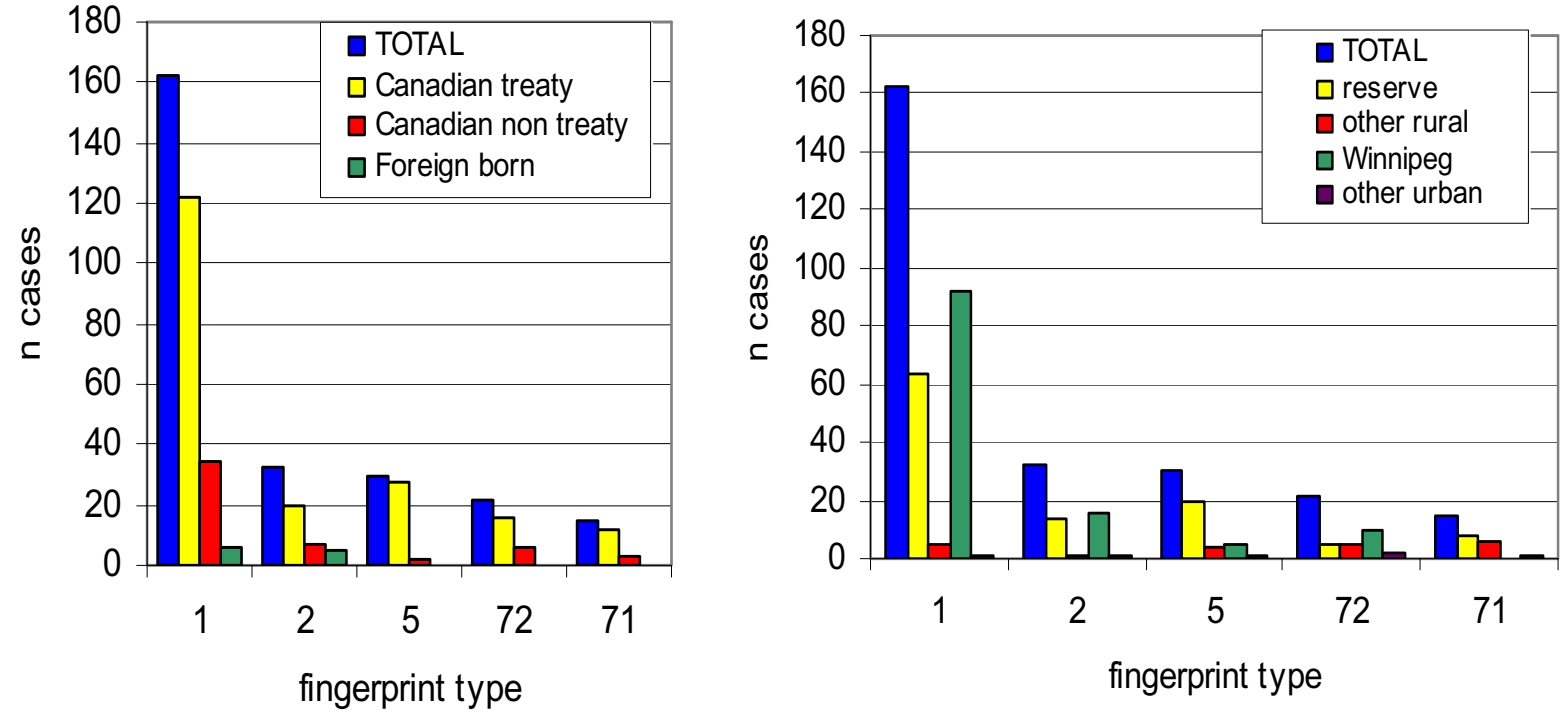

Figure 5

Distribution of the top five prevalent fingerprint types by (a) population subgroup and (b) geographic subgroup, $1992-1999$.

$[9,18]$. It is well established that the foreign-born and Aboriginal groups seem more susceptible to tuberculosis than others within Canada [6,9]. In Manitoba, however, these sub-populations are sustaining the steady level of incidence. Our data demonstrates that TB in Manitoba is a multifaceted problem that can be examined in two distinct, parallel categories. These categories are Canadian $\mathrm{TB}$, where the source of the strains and the patients is Canadian, and foreign TB, where both the patients and strains are from outside Canada.

The major single contributor to the current burden of incident cases is the treaty status subpopulation. The treaty subgroup, with $44.4 \%$ of all tuberculosis cases in Manitoba, comprises the largest group of cases, despite the fact that they represent only $8.9 \%$ of Manitoba's population. This figure is probably an underestimate of all Aboriginal cases due to an unknown number of Aboriginal individu- als who have not claimed treaty status. Moreover, the incidence rate of $\mathrm{TB}$ among the treaty status population (48.4 per 100,000$)$ was higher than both the provincial rate $(9.2$ per 100,000$)$ and the national rate of (5.9 per $100,000)$ by five and eight times respectively. Certain northern First Nation communities have TB incidence rates that are markedly elevated (up to 496.3 per 100000 person-years). Statistical analysis showed the treaty subgroup to be at relatively high risk for the development of $\mathrm{TB}$, with significant independent risk factors for clustering to include male gender, treaty status, and under age 65 .

More than $75 \%$ of the treaty status population group was clustered together by the FP1 strain. Contact tracing revealed only $92(57 \%)$ confirmed epidemiological links within this cluster, living in both Winnipeg and reserve land. Although using both molecular and conventional techniques verifies that linked cases are most likely linked, 

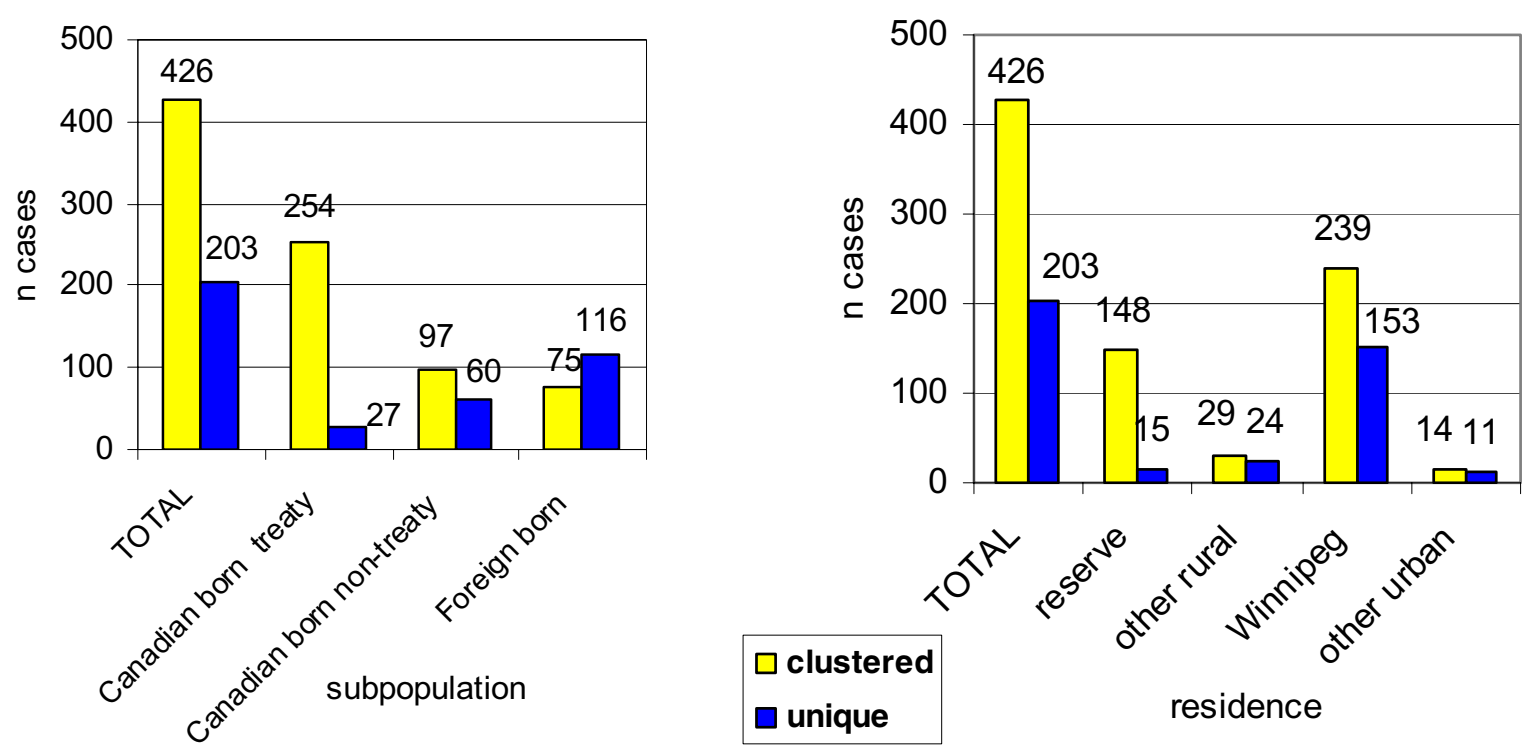

Figure 4

Clustering of fingerprint patterns for (a) population subgroups, (b) geographic subgroups, 1992-1999.

there are limitations to using these techniques [19]. Firstly, transmission can occur through brief, casual contacts, leading to patients having the same fingerprint pattern, yet no definable connection. Secondly, identical RFLP patterns can be obtained from patients that are not linked through recent transmission/reinfection, but due to reactivation. Thirdly, the strain can be inherent in a population, with an unidentifiable source.

However, as clustering is assumed to reflect recent transmission within in a population $[16,19]$, supported by the considerable transmission between family and friends as illustrated by contact investigations, it is highly probable that there is an ongoing, propagating TB outbreak in this subpopulation. The presence of a high percentage of respiratory tuberculosis cases and the large number of positive smear results (data not shown) among FP1 patients suggests that $\mathrm{TB}$ in this population subgroup may be transmitted more efficiently than in other subgroups. Potential factors contributing to increased risk in this subpopulation include: relative poverty, crowded housing, dense social networks, delays in diagnosis and treatment, increased susceptibility to infection due to poorer health status, and increased prevalence of substance abuse. Data on these variables was not available for analysis in the present study. In addition, while the HIV positive group was emerging as an at-risk group for TB in the US, it has not yet been recognized as a risk group in Canada [20]. Thus, the HIV status of tuberculosis patients was not routinely determined in Manitoba until 1997; therefore, complete data on this variable was not available for the current study [21].

The reason for the dominance of FP1 remains unknown, although it has been speculated that perhaps this strain was the first strain introduced to Manitoba. Host genetics, 


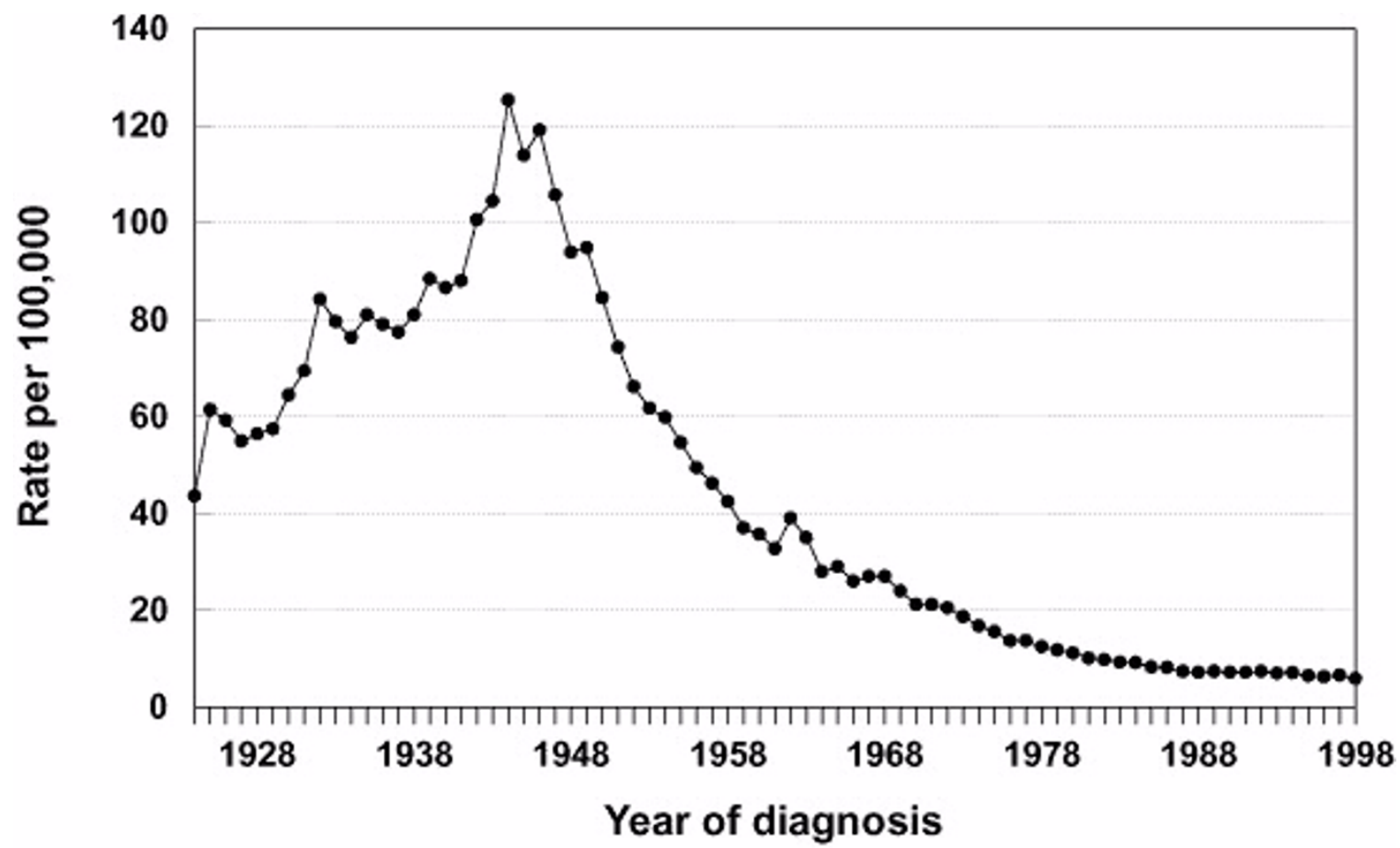

Figure 2

Reported new active and relapsed tuberculosis cases and incidence rate per 100,000 - Canada: 1928-1998.

strain virulence or a combination thereof may play a role $[22,23]$. Routine BCG administration to treaty status infants could have further fostered the natural selection of FP1 by increasing body protection against other susceptible strains through selective immunity. While it is difficult to disentangle social, economic and host risk factors from our analysis, we speculate that this particular strain may be more virulent than other strains introduced to the population. It is possible that this strain shares some features in common with putatively 'hyper virulent' strains CDC 1551 and/ or HN878 [24,25]. Bacterial virulence factors, their expression, regulation and mutation, and host immune system evasion mechanisms may play a role, and this remains to be studied [23].

Winnipeg and nine Aboriginal reserves of northern Manitoba appear to be the two reservoirs that maintain the bulk of clustered TB cases. Patients on reserves were found more than six times as likely to have clustered TB compared to patients in Winnipeg using bivariate analysis. Sixty percent of Manitoba's entire population lives in Winnipeg and there is considerable mobility between Winnipeg and the reserve communities. Since neither geography nor physical distance can provide a barrier to stop the spread of this disease, the types of contact relationships are important factors in elucidating the spread of $\mathrm{TB}$ and differentiating active transmission versus reactivation.

The epidemiological separation between CB and FB tuberculosis cases is the result of many different characteristics. The dominance of unique (non-clustered) fingerprints among foreign-born individuals suggests that these patients may have contracted the disease outside the province and have subsequently imported tuberculosis into Manitoba through immigration. This was found true of 
imported TB in province of Alberta [26]. The age distribution of cases in the foreign-born subgroup reflects the age distribution of immigrants, some of whom for unknown reasons progress to active TB after arrival into Canada. New arrivals into the country may for some time have limited close contact with Canadian-born individuals, which reduces the chance of spread from immigrants to the $\mathrm{CB}$ population. The small amount of clustering that does occur in the FB subpopulation may be explained largely by activation of infections acquired from common sources in the foreign country of origin. In Manitoba, FB TB patients reside largely in the Winnipeg area and spread of the disease from $F B$ patients to $C B$ individuals is very limited (data not shown).

While the foreign-born population may not seem to be actively spreading TB in Manitoba, incidence rates are still relatively high, and the number of FB cases reported annually is increasing. Screening procedures for immigrating individuals from countries with high or low prevalence of $\mathrm{TB}$ need further examination for effectiveness and costeffectiveness [27].

In the present study, information derived from both conventional and molecular epidemiology methods allowed assessment of current trends and risk factors for subpopulation groups in Manitoba for contracting TB. Retrospective studies such as this one using stored RFLP data have shown invaluable to identify both clinical and epidemiological risk factors for clustering, and have been used extensively to study other populations within San Francisco, New York and the Netherlands $[17,19,28,29]$. This information helps assess the effectiveness and possible limitations of the Manitoba TB control programs. Elimination of TB has been defined as less than 1 case per 100,000 population per year $[6,8]$. By this standard, recent transmission to Canadian-born non-treaty status individuals has been nearly eliminated, reaching incidence rates of only 3.3 per 100,000. Complete elimination of TB in Manitoba has been targeted for 2010, with $5 \%$ reduction in incidence per year goal $[6,8]$, but with the high incidence rates in the remaining two sub-populations, this will be a difficult task. Targeting and intensifying control measures in the immigrant and treaty status Aboriginal subpopulations should be a priority in striving for the goal of tuberculosis elimination in Manitoba.

\section{Competing Interests}

None declared.

\section{Authors' Contributions}

KB coordinated / drafted the final manuscript. AA carried out the data extraction, statistical analysis and initial draft. LE edited and participated/revised in statistical analysis. $\mathrm{EH}$ and AK provided the data, designed and supervised the use of the data for the manuscript. All authors read and approved of the final manuscript.

\section{References}

I. Fanning EA: Globalization of tuberculosis. CMAJ 1998, 158:6I|-6|2.

2. Piheu JA: Tuberculosis 2000: problems and solutions. Int J Tuberc Lung Dis 1998, 2:696-703.

3. Raviglione MC, Snider DE and Kochi A: Global epidemiology of tuberculosis: morbidity and mortality of a worldwide epidemic. JAMA 1995, 273:220-226.

4. Grzybowski $S$ and Allen EA: Tuberculosis: 2. History of the disease in Canada. CMAJ 1999, 160:1025-1028.

5. Wherret G]: Tuberculosis in Canada. Ottawa: Royal Commission on Health Services 1964.

6. Canada Communicable Disease Report. Supplement: Proceedings of the national consensus conference on tuberculosis. Health Canada 1997, 24S2:.

7. Long R and ed: Canadian Tuberculosis Standards. Canadian Lung Association and Health Canada 52000.

8. Health Canada: Tuberculosis in the First Nations, 1999. Health Canada, Canada 1999. (Cat.H35-4/7-1999E) (ISBN 0-662-30044-0)

9. Long R, Njoo $\mathrm{H}$ and Hershfield E: Tuberculosis: 3. Epidemiology of the disease in Canada. CMAJ 1993, 160:1185-1190.

10. Al-Azem A, Abomoelak B, Wolfe J, MacMorran J, Hershfield E and Kabani A: Tuberculosis in Manitoba: Conventional and molecular epidemiology (1992-1999) [abstract]. Public Health Poster Session (ATS) 2000. CDC-NCHSTP-DTBE

II. Al-Azem A, Abomoelak B, Wolfe J, MacMorran J, Hershfield E and Kabani A: Rural and localized tuberculosis outbreaks in Manitoba (1992-1999) [abstract]. Public Health Poster Session (ATS) 2000. CDC-NCHSTP-DTBE

12. Dimensions Series: Portrait of Aboriginal Population in Canada. Ottawa, ON: Statistics Canada 1999. [94F00IIXCB]

13. Live Database 1992-1997, Indian Registry System, Indian and Northern Affairs Canada. Manitoba Region .

14. van-Embden JD, Cave MD, Crawford JT, Dale JW, Eisenach KD, Gicquel B, Hermans P, Martin C, McAdam R and Shinnick TM: Strain identification of Mycobacterium tuberculosis by DNA fingerprinting: recommendations for a standardized methodology. J Clin Microbiol 1993, 3 1:406-409.

15. Small PM, McClenny NB, Singh SP, Schoolnik GK, Tompkins LS and Mickelsen PA: Molecular strain typing of Mycobacterium tuberculosis to confirm cross- contamination in the mycobacteriology laboratory and modification of procedures to minimize occurrence of false-positive cultures. J Clin Microbiol 1993, 31:1677-82.

16. Rhee JT, Tanaka MM, Behr MA, Agasino CB, Paz EA, Hopewell PC and Small PM: Use of multiple markers in population-based molecular epidemiologic studies of tuberculosis. Int J Tuberc Lung Dis 2000, 4:1111-1119.

17. Shafer RW, Small PM, Larkin C, Singh SP, Kelly P, Sierra MF, Schoolnik $G$ and Chirgwin KD: Temporal trends and transmission patterns during the emergence of multidrug-resistant tuberculosis in New York City: a molecular epidemiologic assessment. J Infect Dis 1995, I 7 I: 170-76.

18. Al-Azem A, Abomoelak B, Wolfe J, MacMorran J, Hershfield E and Kabani A: The impact of foreign-born tuberculosis in Manitoba (1992-1999) [abstract]. Public Health Poster Session (ATS) 2000. CDC-NCHSTP-DTBE

19. Small PM, Hopewell PC, Singh SP, Paz A, Parsonnet J, Ruston DC, Schechter GF, Daley CL and Schoolnik GK: The epidemiology of tuberculosis in San Francisco. A population based study using conventional and molecular methods. N Eng J Med I 994, 330: 1703-1709.

20. Gaudette LA and Ellis E: Tuberculosis in Canada: a focal disease requiring distinct control strategies for different risk groups. Tuber Lung Dis 1993, 74:244-53.

21. Yuan L, Carew M, Kwavnick B and Trudel N: Medical services branch tuberculosis program and epidemiologic review. Health Canada, Canada 1999.

22. Stead WW: Variation in vulnerability to tuberculosis in America today: random, or legacies of different ancestral epidemics? Int J Tuberc Lung Dis 200I, 5:807-8I4. 
23. Kato-Maeda M, Bifani PJ, Kreiswirth BN and Small PM: The nature and consequence of genetic variability within Mycobacterium tuberculosis. J Clin Invest 200I, 107:533-537.

24. Manca C, Tsenova L, Barry CE III, Bergtold A, Freeman S, Haslett PA, Musser JM, Freedman VH and Kaplan G: Mycobacterium tuberculosis CDCI55 I induces a more vigorous host response in vivo and in vitro, but is not more virulent than other clinical isolates. I Immunol 1999, 162:6740-46.

25. Manca C, Tsenova L, Bergtold A, Freeman S, Tovey M, Musser JM, Barry CE III, Freedman VH and Kaplan G: Virulence of a Mycobacterium tuberculosis clinical isolate in mice is determined by failure to induce ThI type immunity and is associated with induction of IFN-alpha /beta. Proc Natl Acad Sci USA 200I, 98:5752-57.

26. Cowie RL and Sharpe JW: Tuberculosis among immigrants: interval from arrival in Canada to diagnosis. A 5-year study in southern Alberta. CMAJ 1998, I 58:599-602.

27. Schwartzman $K$ and Menzies $D$ : Tuberculosis screening of immigrants to low-prevalence countries: a cost-effectiveness analysis. Am J Respir Crit Care Med 2000, I6 I:780-789.

28. Jasmer RM, Hahn JA, Small PM, Daley CL, Behr MA, Moss AR, Creasman JM, Schecter GF, Paz EA and Hopewell PC: A molecular epidemiologic analysis of tuberculosis trends in San Francisco, 199 I-1 997. Ann Intern Med 1999, I 30:97|-978.

29. Borgdorff MW, Nagelkerke N, van Soolingen D, de Haas PE, Veen J and van Embden JD: Analysis of tuberculosis transmission between nationalities in the Netherlands in the period 19931995 using DNA fingerprinting. Amer J Epidem 1998, | 47: $187-195$.

\section{Pre-publication history}

The pre-publication history for this paper can be accessed here:

http://www.biomedcentral.com/1471-2334/3/18/prepub

Publish with Bio Med Central and every scientist can read your work free of charge

"BioMed Central will be the most significant development for disseminating the results of biomedical research in our lifetime. "

Sir Paul Nurse, Cancer Research UK

Your research papers will be:

- available free of charge to the entire biomedical community

- peer reviewed and published immediately upon acceptance

- cited in PubMed and archived on PubMed Central

- yours - you keep the copyright 